\title{
Field-Emission Cathode Micro-Electro-Mechanical System Technology for Sensors, Diagnostics, and Microelectronics
}

\author{
Jeffrey D. Morse, Jackson C. Koo, and Robert T. Graff \\ Electronics Engineering Technologies Division, Electronics Engineering \\ Alan F. Jankowski and Jeffrey P. Hayes \\ Materials Science and Technology Division, Chemistry and Materials Sciences
}

March 30, 1998

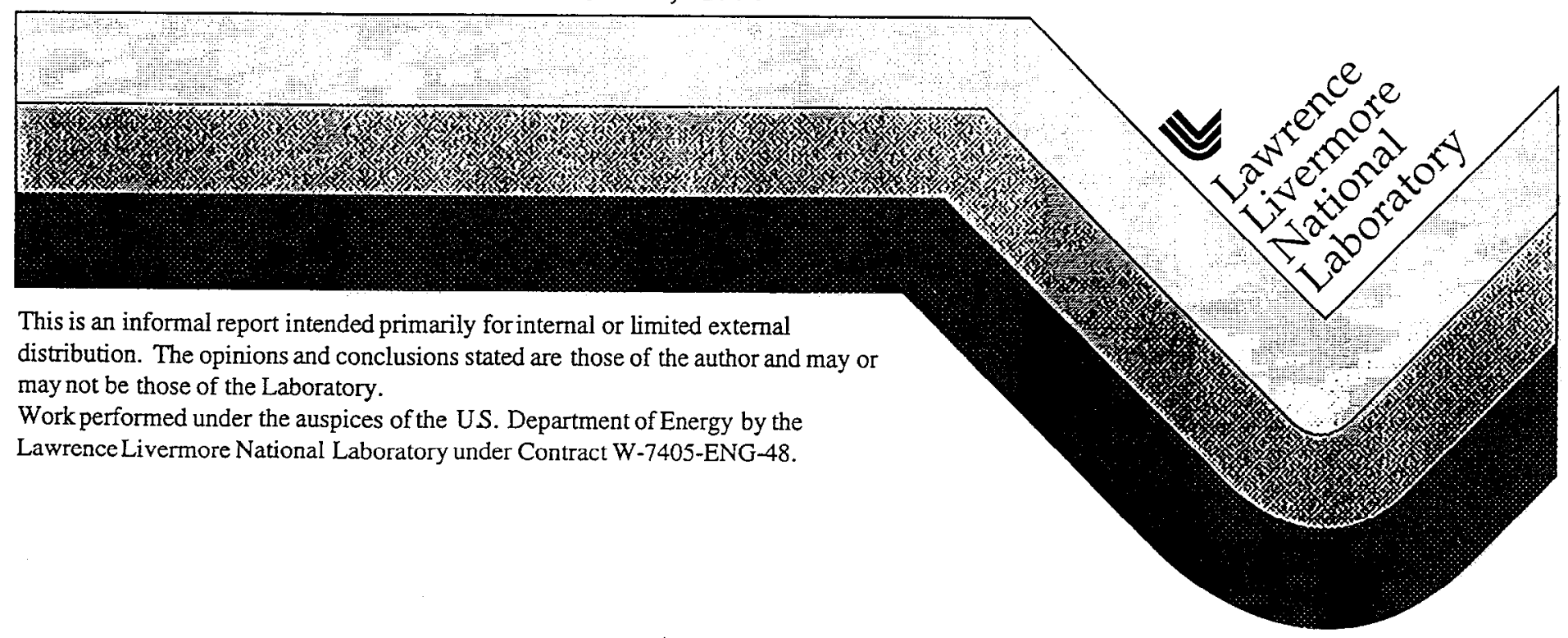




\section{DISCLAIMER}

This document was prepared as an account of work sponsored by an agency of the United States Government. Neither the United States Government nor the University of California nor any of their employees, makes any warranty, express or implied, or assumes any legal liability or responsibility for the accuracy, completeness, or usefulness of any information, apparatus, product, or process disclosed, or represents that its use would not infringe privately owned rights. Reference herein to any specific commercial product, process, or service by trade name, trademark, manufacturer, or otherwise, does not necessarily constitute or imply its endorsement, recommendation, or favoring by the United States Government or the University of California. The views and opinions of authors expressed herein do not necessarily state or reflect those of the United States Government or the University of California, and shall not be used for advertising or product endorsement purposes.

This report has been reproduced directly from the best available copy.

Available to DOE and DOE contractors from the Office of Scientific and Technical Information

P.O. Box 62, Oak Ridge, TN 37831

Prices available from (615) 576-8401, FTS 626-8401

Available to the public from the

National Technical Information Service

U.S. Department of Commerce

5285 Port Royal Rd.,

Springfield, VA 22161 


\title{
Field-Emission Cathode Micro-Electro-Mechanical System Technology for Sensors, Diagnostics, and Microelectronics
}

\author{
Jeffrey D. Morse, Jackson C. Koo, and Robert T. Graff \\ Electronics Engineering Technologies Division \\ Electronics Engineering
}

\author{
Alan F. Jankowski and Jeffrey P. Hayes \\ Malerials Science and Technology Division \\ Chemistry and Materials Sciences
}

We have investigated field-emission devices for applications in sensors, diagnostics, and microelectronics. Field-emission devices micromachined from silicon and molybdenum have been fabricated and tested. Experimental results have shown that the presence of nitrogen gas molecules for pressures up to $1 \mathrm{~m}$ Torr has only a moderate impact on device emission performance, and has no long term effect on device operation. These results demonstrate that field-emission cathodes can potentially be used in sensors applications where gas ionization by electron impact is desirable, or other applications in which the field-emission device is exposed to less than ideal vacuum conditions.

\section{Introduction}

A substantial level of interest from Lawrence Livermore National Laboratory (LLNL) programs, government agencies, and the private sector has been generated to use miniature electron sources for a variety of applications, including ion gages, ion cells, cathodes for $\mathrm{x}$-ray sources, and radiation hard microelectronics.

In most cases, a solid-state field-emission cold cathode would replace a thermionic emitter, or filament. Of these applications, several stand out as having significance for LLNL programs and Department of Energy (DOE) directives. Ihese include radiation hard vacuum microelectronics; electron sources for miniature $\mathrm{x}$-ray sources having remarkably small spot sizes for imaging, diagnostics, and instrumentation; field-emission cathodes (FECs) as an electron source for an ion cell in a portable mass spectrometer, ${ }^{1}$ and as an ion cell detector for potential use in gas chromatography. ${ }^{2}$

'The last application, which is the focus of this report, requires critical understanding of microelectro-mechanical (MEMs) systems design, along with integration of field-emission devices, to realize a new micro-sensor technology. The advantage is that a low cost, micro-miniature, gas-molecule detector sub-system technology can be realized, with improved sensitivity over existing detectors. Furthermore, this ion cell can be integrated for specific application to gas chromatography systems. This technology would support industrial and environmental programs for the monitoring of toxics, pesticides, and petroleum products. In these applications parts-per-billion sensitivity is required in compact, portable systems.

At present gas-molecule detection schemes consist of several approaches, including helium ionization detection (HID), electron capture detection (ECD), both of which are highly sensitive (many parts per billion), and thermal conductivity detectors (ICD), with sensitivity limited to a few parts per million.

The ECD is more selective, being limited to sample molecules having sufficient electron capture cross-sections, such as pesticides and PCBs. ECDs therefore are useful in environmental monitoring applications. HIDs are more universal in the range of gas sample molecules that can be detected. This system implements a windowless photo-ionization system in which a carrier gas (helium or doped helium) is ionized by pulsed discharge. The UV 
radiation then propagates to the detection region where it ionizes the sample gas without exciting the carrier gas. The free electrons are then collected by an electrode with a current peak corresponding to the sample molecule. Presently, these high sensitivity detection systems suffer from the nccd for a pulse discharge or radioactive source to generate ionizing $U V$ radiation.

Unfortunately, these approaches are neither desirable nor conducive to micro-miniaturization, low cost, and high performance.

\section{Progress}

Gated field-emission, cold-cathode electron sources were evaluated as an improved means to generate electrons that could subsequently be used as an ionization source. The concept is illustrated in Fig. 1. Field-emission devices are cathode structures that are formed to atomically sharp tips which are in the proximity of an extraction, or gate electrode. By applying a positive voltage to the gate electrode with respect to the cathode, electrons are emitted into the vacuum above the gate, where they are swept away by the anode electric field. The efficiency of the field-emission process depends on the gate-to-tip spacing, the shape of the tip, and the effective work function of the tip material.

The potential advantages of field-emission devices as an electron source are improved efficiency, addressability and control, no heating of surrounding areas, and faster turn-on. Furthermore, field emitters are made using standard microfabrication processes, thus are more conducive to implementation into arrays, specific cathode designs, and integration with other microfabricated components.

These advantages can impact the performance of an ionization source in several ways. First, the FEC is controlled by a gate electrode, therefore is electrically addressable, and uses only a fraction of the power of filaments or pulse discharge electrodes. Ficld-cmission devices can bc integratcd within the gas microflow system to directly ionize the sample gas, or bc used in a manner to generate UV photons by ionizing a carrier gas, such as helium. The UV photons subsequently ionize the samplc gas molecules. Thus, field emitters enable more flexibility and lower power usage in the ionization and detection scheme.

An FEC array was designed having an active emission area ranging from $25 \mu \mathrm{m} \times 100 \mu \mathrm{m}$ (800 emitters) to $100 \mu \mathrm{m} \times 200 \mu \mathrm{m}(10,000$ emitters). Figure 2 illustrates the fabrication sequence for making a gated FEC device using the Spindt cathode technique. ${ }^{3-5}$ Using a proprietary lithographic technique developed at LLNL, gate-totip spacings of $<0.1 \mu \mathrm{m}$ have been achieved, as illustrated in Fig. 3. Process development consisted of several iterations of this sequence to optimize problems associated with adhesion of thin films, uniformity of emitters, gate hole diameter, pattern transfer, and gate-to-cathode leakage current. While most of these issues have been addressed and resolved, the issue of gate leakage current remains problematic.

A vacuum test station has been assembled to characterize the FECs at pressures on the order of $10^{-7}$ Torr. The test apparatus includes a fixture on which the FEC is mounted and electrical leads attached. The anode is then positioned to within $0.5 \mathrm{~mm}$ of the cathode array to collect any electrons that are emitted. Vacuum testing of these devices has demonstrated field-emission current turn-on with less than $50 \mathrm{~V}$ applied to the gate electrode.

As previously mentioned, a limitation of devices fabricated is the excessive gate leakage current

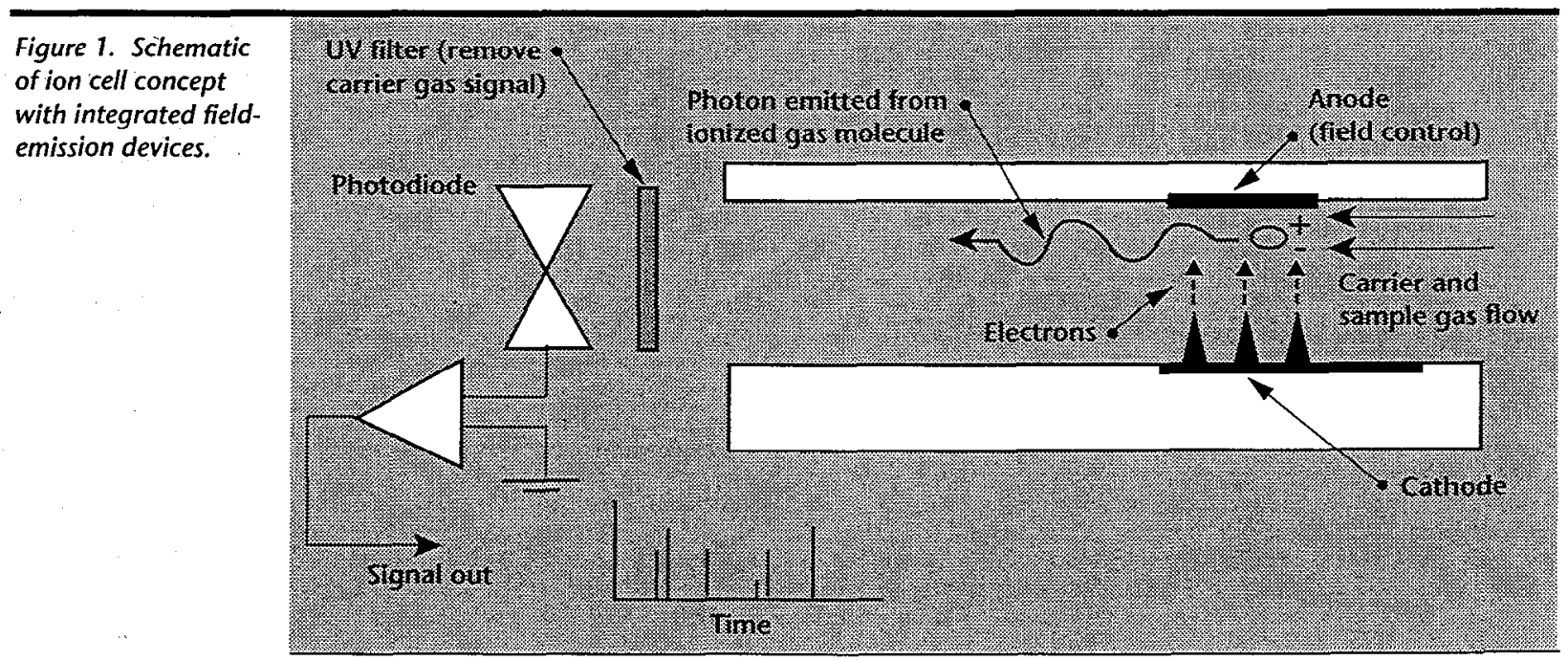




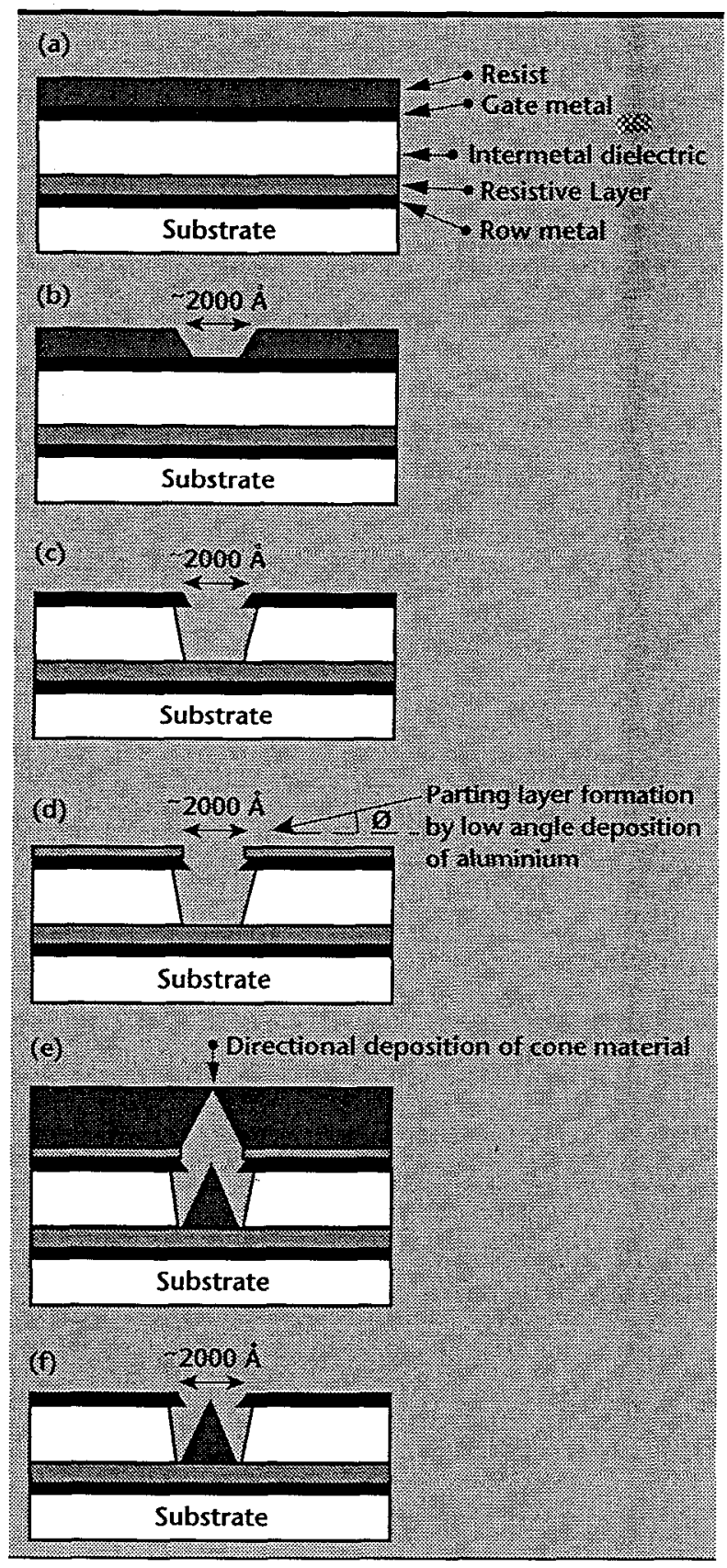

Figure 2. Cross-sectional schematic diagram of field-emission cathode fabrication process sequence: a) initial stack of thin film layer with resist deposited on top; b) patterning of resist by lithographic techniques to form gate structure; c) etching of the gate metal through the mask and the cavity in the intermetal dielectric; d) field-emitter tips formed by depositing a parting layer; and e) directional deposition of the tip material. The final emitter structure $(f)$ is formed after lifting the parting layer from the gate metal.

which is orders of magnitude greater than the emission current, as illustrated in Fig. 4. This problem is being addressed, and is likely a result of contamination in the intermetal dielectric, or metal, shorting the tip directly to the gate electrode. Further iterations should resolve this problem. The impact on

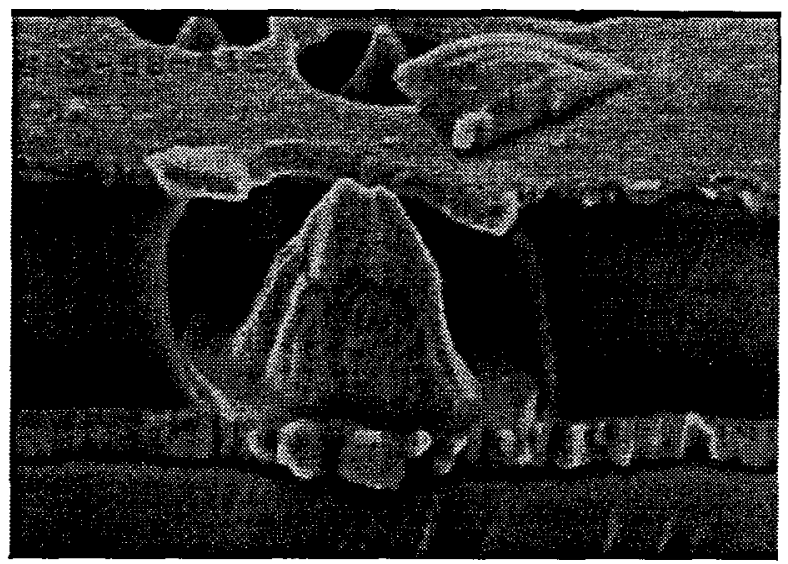

Figure 3. Gated field-emission cathode fabricated using sequence shown in Figure 1. Gate diameter for this device is $2000 \AA$.

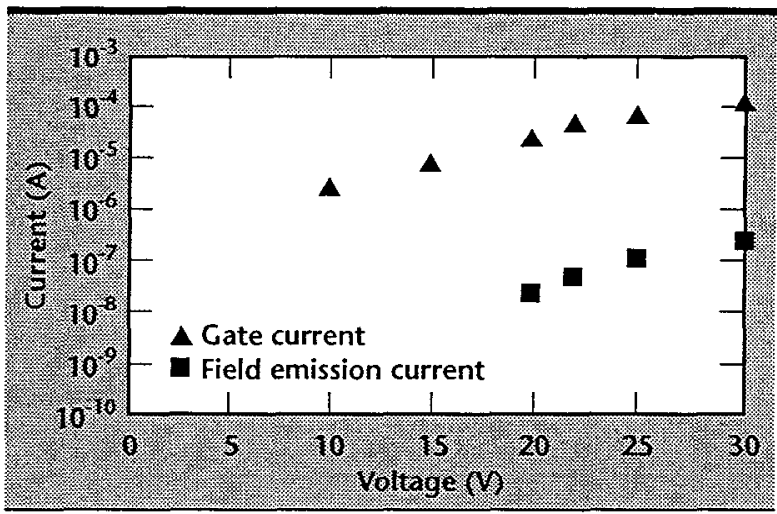

Figure 4. Current/voltage characteristics for field-emission cathode array. Current, measured at anode with $1.5 \mathrm{kV}$ applied, and gate electrode, are illustrated as a function of gate-to-cathode voltage.

device performance is that the FEC will burn out when the gate current reaches some value, on the order of $100 \mu \mathrm{A}$, thus limiting the field-emission current to about $50 \mathrm{nA}$. Other solutions to this problem include an integrated ballast resistor. which in effect will minimize the impact of shorting due to point defects.

Arrays of ungated, silicon field emitters were fabricated and tested. The silicon tips were created by patterning a silicon nitride mask on heavily doped, n-type silicon. The silicon was then isotropically etched, undercutting the nitride mask, until the silicon formed a relatively sharp point. The silicon tip arrays are illustrated in Fig. 5.

The silicon field-emitter array was mounted on the test fixture, and positioned in the vacuum test chamber, with an anode spacing of approximately $500 \mu \mathrm{m}$ above the tips. Field-emission current was then monitored as the anode voltage was increased. These characteristics were monitored as the pressure was increased by introducing nitrogen to the chamber. 


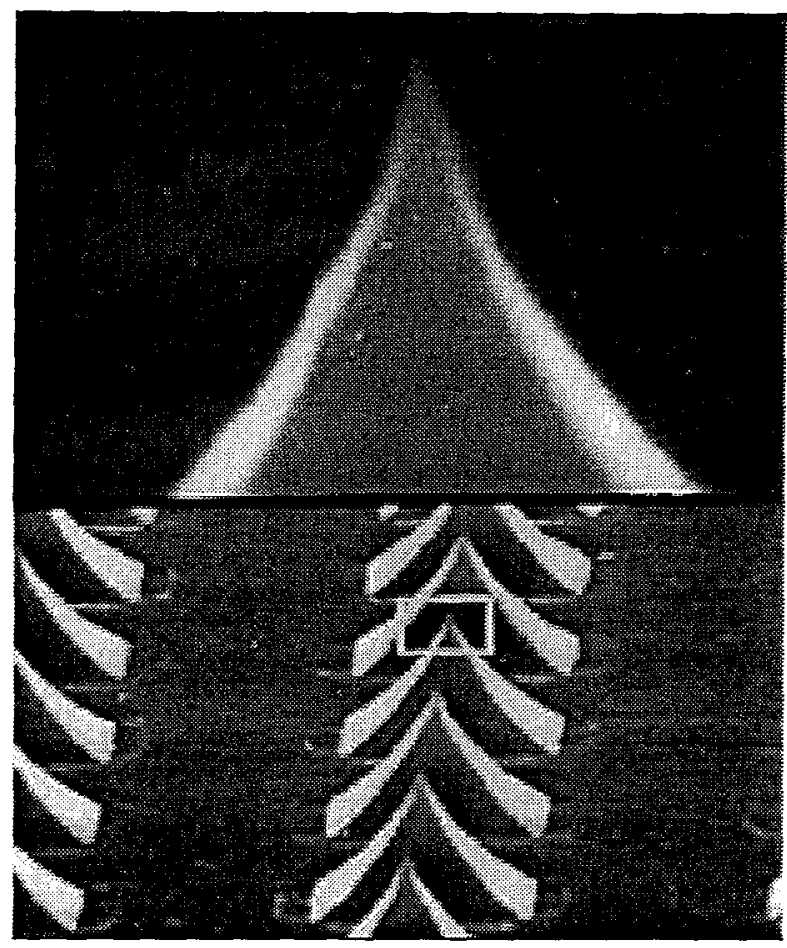

Figure 5. Scanning electron micrograph of silicon fieldemission tip arrays.

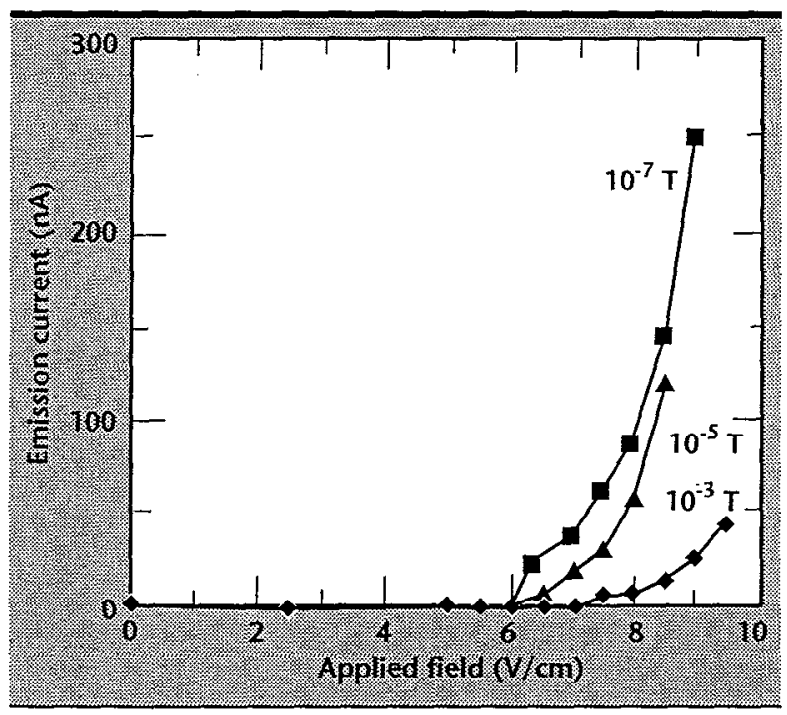

Figure 6. Experimentally measured current/voltage characteristics of silicon field-emitter tip array with varying nitrogen pressure.
The performance of the silicon emitter array at various pressures is illustrated in Fig. 6. We observed that the relative field-emission current decreases at higher pressures, likely resulting from increased scattering of the emitted electrons with the gas molecules. Upon further inspection of the silicon tip array after testing, we observed no physical damage to the devices.

\section{Future Work}

Ionization sources are finding increased uses for a variety of applications. Efforts to further evaluate the performance of field-emission devices in nonideal vacuum, and higher gas flow conditions are continuing, to understand the optimal design and performance for this application. Once completely evaluated, field-emission devices can be integrated with microflow components, to realize a MEMSbased micro-analytical instrument for detection and identification of trace chemical species.

\section{References}

1. Spindt, C. A. (1992), "Microfabricated field-emission and field-ionization sources," Surface Science, North Holland, 266, pp. 145-154.

2. Snyder, A. P., C. S. Harden, A. H. Brittain, M-G. Kim, N. S. Arnold, and H. L. C. Meuzelaar (1996). "Portable Hand-held Gas Chromatography/Ion Mobility Spectrometry Device," Analytical Chemistry, February, Vol. 65, (3), pp. 299-306.

3. Spindt, C. A., I. Brodie, L. Humphrey, and E. R. Westerberg (1976), "Physical properties of thinfilm field-emission cathodes with molybdenum codes," J. Appl. Phys., 47 (12), p. 5248.

4. Spindt, C. A., C. E. Holland, P. R. Schwoebel, and I. Brodie (1996), "Field-Emitter-Array Development for Microwave Applications," I. Vac. Sci. Technol. B, 14 (3), p. 1986.

5. Bozler, C. O., C. T. Harris, S. Rabe, D. D. Rathman, and M. A. Hollis (1994), "Arrays of Gated FieldEmitter Cones Ilaving 0.32- $\mu \mathrm{m}$ Tip-To-Tip Spacing," $J$. Vac. Sci. Technol. B, 12 (2), p. 629. 


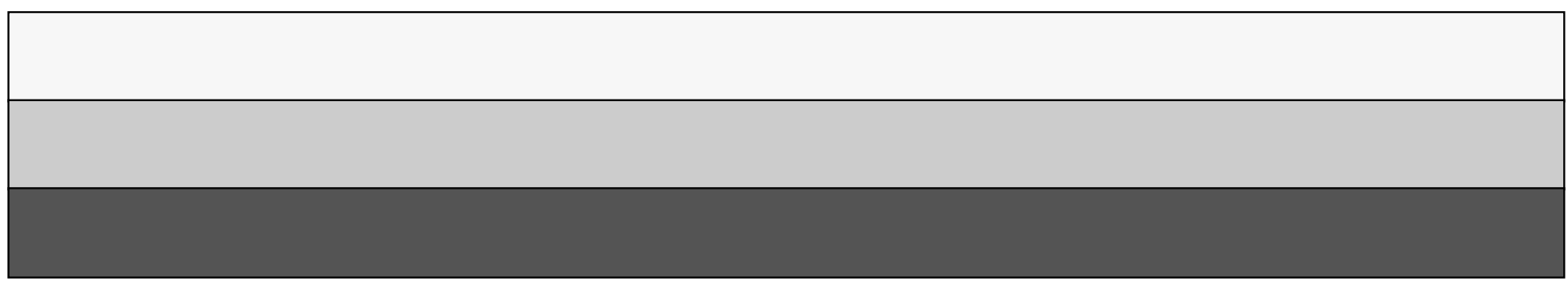

